\title{
CLASSIFIER ASSIGNMENT BY CORPUS-BASED APPROACH
}

\author{
Virach Sornlertlamvanich \\ Wantanee Pantachat \\ Linguistics and Knowledge Science Laboratory \\ National Electronics and Computer Technology Center \\ National Science and Technology Development Agency \\ Ministry of Science Technology and Environment \\ 22nd Gypsum Metropolitan Tower, \\ 539/2 Sriayudhya Rd., Bangkok 10400, Thailand \\ [virach,wantanee,surapan\}@ @ nw.nectec.or.th
}

Surapant Mekmavin

\begin{abstract}
This paper presents an algorithm for selecting an appropriate classificr word for a noun. In Thai language, it frequently happens that there is fluctuation in the choice of classifier for a given concrete noun, both from the point of vicw of the whole specch community and individual speakers. Basically, there is no exact rule for classifier selection. As far as we can do in the rule-based approach is to give a default rule to pick up a corresponding classifier of each noun. Registration of classifier for each noun is limited to the type of unit classifier because other types are open due to the meaning of representation. We propose a corpus-based method (Biber,1993; Nagao,1993; Smadja,1993) which generates Noun Classifier Associations (NCA) to overcome the problems in classifier assignment and semantic construction of noun phrase. The NCA is created statistically from a large corpus and recomposed under concept hierarchy constraints and frequency of occurrences.
\end{abstract}

Keywords: Thai language, classifier, corpus-based method, Noun Classifier Associations (NCA)

\section{Introduction}

A classifier has a significant use in Thai language for construction of noun or verb to express quantity, determination, pronoun, etc. By far the most common use of classifiers, however, is in enumerations, where the classifiers follow numerals and precede demonstratives (Noss, 1964). Not all types of classifier have a relationship with noun or verb as a unit classifier does.

A unit classifier is any classifier which has a special relationship with one or more concrete nouns. For example, to enumerate members of the class of /rya/ 'boats', the unit classificr /lam/ is selected as in the phrase below:

เรือ หนึ่ง ถ๋า
/rya nung lam/
boat one <boat>
'one boat'.

Other than the unit classifier, there are collective classifier, metric classifier, frequency classifier and verbal classifier.

A collective classifier is any classifier which shows general group or set of mass nouns, แn สอง ฝูง fnok soong fung/ 'two flocks of bird'. A metric classificr is any classifier which occurs in enumerations that modify predicates as well as nouns, น้ำ สาม แก้ว /nam saam kaew/ 'threc glasses of water'.

A frequency classifier is any classifier which is used to express the frequency of event that occurs, บิน สี่ รยบ /bin sii roob/ 'fly four rounds'. A verbal classifier is any classifier which is derived from a verb and usually used in construction with mass nouns, กระคาษ ท้า ม้วน /kradaad haa muan/ 'five rolls of paper'.

The unit classifier has a special relationship with concrete noun. The member of this class of classifier is closed for each noun. Most of the unit classifiers are used with a great many concrete nouns of very different meaning, but few are restricted to a single noun. Except for the unit classifier, the members of classificr for a noun or predicate are open. Especially for the metric classifier, the number of classifiers for numeral expression of distance, size, weight, container and value is large.

The use of classifier in Thai is not limited to the numeral expression but is extended to other expressions such as ordinal, determination, relative pronoun, pronoun, etc. The detail of each classifier phrase is described in the next section.

In many existing natural language processing systems, the list of available classifiers for each noun is attached to a lexicon base. Rules for classifier selection from the list can somehow provide the 
default value but does not guatantec the appropriateness. However, the problems on classifier phrase construction still remain unsolved.

To overcome the problems of using classifiers, we propose a method of classifier phrase extracting from a large corpus. As a result, NounClassifier Associations (described in Scction 3) is statistically created to define the relationship between a noun and a classificr in a classifier phrase. With the frequency of the occurrence of a classifier in a classificr phrasc, we can propose the most appropriate use of a classifier. Furthernore, we introduce a hierarchy of semantic class for the induction of a classifier class when they are employed to construct with nouns which belong to the same class of meaning. Section 3 and Section 4 describe the generation and the implementation of the NCA, respectively.

\section{The roles of classifies in 'Thai language}

In Thai language, we use classifiers in various situations. The classificr plays an important rok in construction with noun to express ordinal, pronoun, for instance. The elassifice phrase is syntactically generated according to a specific pattern. Fig. 2.1 shows the position of a classifiter in cach pattern, where $\mathbb{N}$ stands for noun, NCNM stands for cardinal number, Cl. stands for classitier, DET stands for determiner, VATT stands for attributive verb, RLLL. $M$ stands for relative marker, rTR $M$ stands for Interrogative niarkes, DONM stands for ordinal nuncral, DDAC stauds for dofinte demonstiative

Study on the use of clissificr in each expression inentioned above, we can conclude that the rypes of classifier atre not restricted to any kinds of expression. To consider the semantic representation of each cxpression, it happeras that the unit classifice is not regarded as a conceptual mit in all expressions execpt in pattern 6 , but the siher types ates (sec examples in a. and b.)

a) $15 \% 31$ เพน

/prachachon 2 khou

(Unît-CI..)

people: 2 cocople

"2. propile'

b) ปมะชาชบ สอง กตุม

fprachachon 2. klumi

(Collective-CI.)

people $2<$ grouplo

2 groups of people'

We encountered to generate the appropriate classifier for noun or verb in a semantic represcitation. The classificr assignment for non-conceptual representation and the classifice selection of one to many conceptual representation are over handleable by the rule-based approach. The propose on classifier assignment using the corpus-based method is another approach. Based on the collocation of noun and classifier of each pattern shown in Fig. 2.1, we decided to construct the Noun Classifier Association table (sec Section 3). A stochastic method combined with the concept hicrarchy is proposed as a strategy in making the NCA table. The table composes of the information about noun-classifier collocation, statistic occurrences and the representative classifier for each semantic class in the concept hierarchy.

\section{Extraction of Noun-Classifier Collocation}

In this section, we describe the algorithm used for extraction of Noun Classifier Associations (NCA) from a large corpus. We used a 40 megabyte Thai corpus collected from various areas to create the table. The algorithm is as follows:

Step 1: Word segmentation.

Input: $\Lambda$ corpus.

Output: The word-segmented corpus.

In text processing, we often need word boundary information for several purposes. Because Thai has no explicit marker to separate words from one another, we have to preprocess the corpus with word segmentation program. We used the program developed by Somlentlamvanich (1993) with post-editing to correct fault segmentation. 'The program employs heuristic rules of longest matching and least word count incorporated with character combining rules for Thai words. Though the accuracy of the word segmentation does not reach $100 \%$, but it is high enough (more than $95 \%$ ) to reduce the post-editing time.

Step 2: Tagging.

Input: Output of step 1 .

Output: The corpus of which each word is tagged with a part of speechi and a semantic class.

The word-segmented corpus is then processed with a stochastic part-of-speech tagger. Each word $w$ together with its part of specch is then used to retrieve the semantic class of the word from a dictionary. The result yields a data structure of $(w, p, s)$, where $p$ denotes the part of specch of $w$ and $s$ denotes the scrnantic class of $w$. For example, the data structure of the word ขักเรียน /nakrian/ 'student' is (นักเรียน, NCMN, person), where NCMN stands for common noun and porson represents นักเรียน in the class of person.

Step 3: Producing concordances.

Input: Output of step 2, a given classifier $\mathrm{cl}$. Output: All the fragments containing $c l$. 


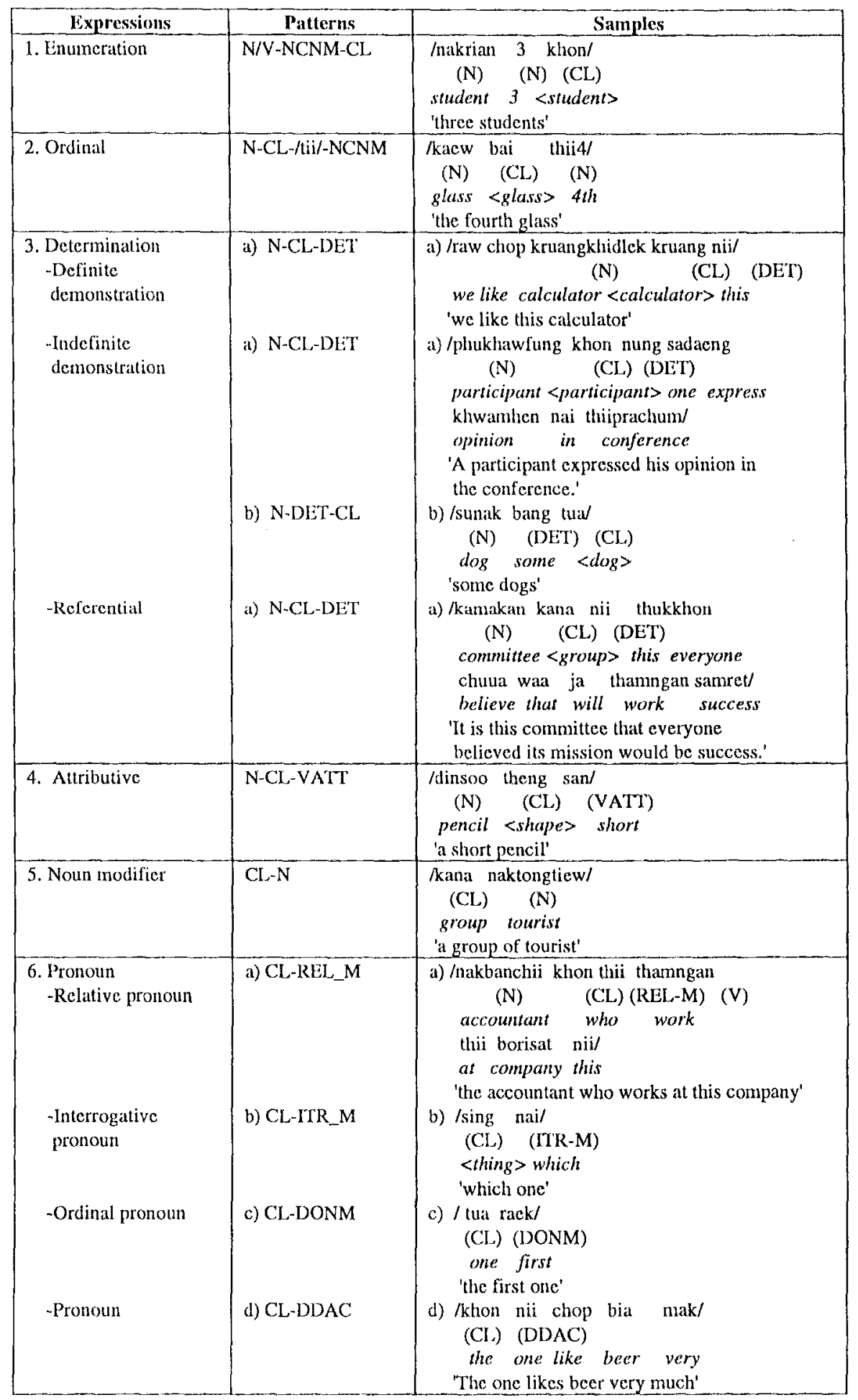

Fig. 2.1 Classification of classificr expressions table 


\begin{tabular}{|c|c|}
\hline (คณะกรรมการ_111, คนะะ_2, 11) & (ทหาร_111, หาย_1, 9) \\
\hline (คณะกรรมการ_111, กลุ่ม_2, 5) & (ทหาร_111, ฝ่าย_2, 1) \\
\hline (คนนะกรรมการ_ 111, คน_1, 6) & (คนงาน_111, คน 1,6$)$ \\
\hline (นก 13111, ตัว_1, 9) & (ต้ม_13114, สูก_1, 12) \\
\hline$($ Hn_13111, ฝูง 2, 4) & (ล้ม_13114. ผล__, 3) \\
\hline (ไก่_13111, ตัว 1,10 ) & (แตงโม_13114, ลูก_1, 8) \\
\hline (ไก่_13111, เล้า_2, 3) & (ทุเรียนเ13114, ลูก_1,9) \\
\hline (นกกระจอก_13111, ตัว 1,7 ) & $($ โศโ_, 13111, ตัว_1, 7) \\
\hline (คน__111, คนน_1, 67) & (หมา_13111, ตัว_1, 13) \\
\hline (คน_111, กสุ่ม_2,1) & (หมู_ 13111, ตัว_1, 5) \\
\hline (ทหาร..111, คนณ_1, 17) & (ช้าง 13111 เ เชิอก_1, 3) \\
\hline
\end{tabular}

Fig. 3.1 Table of Noun Classificr Associations (NCA)

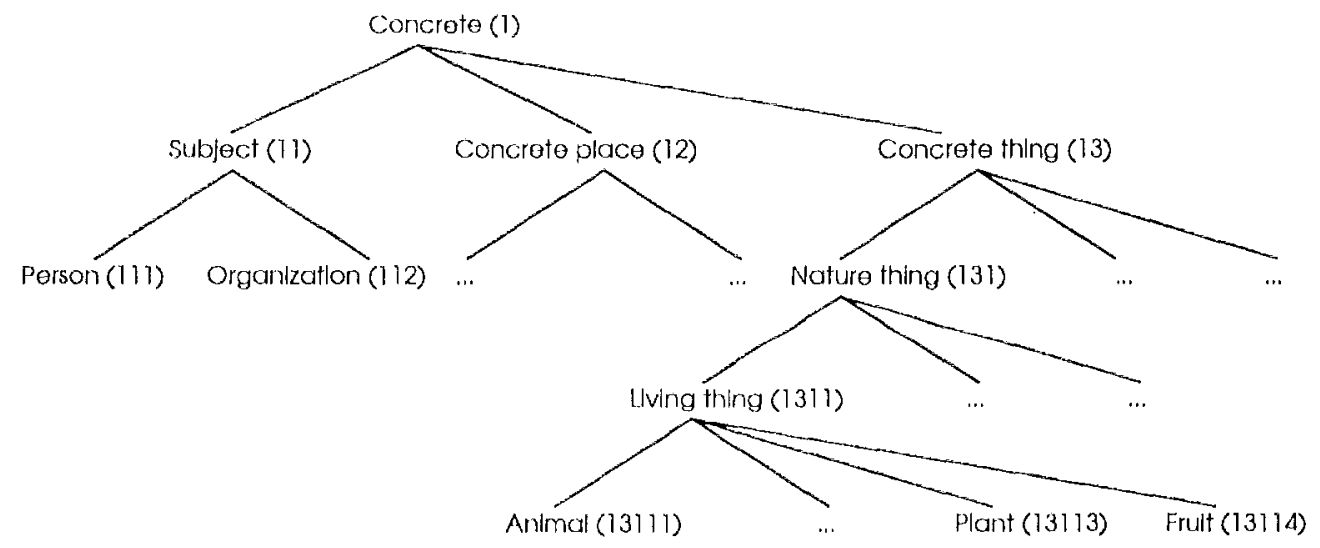

Fig. 3.2 Concept hicratchy

Instead of picking up the data sentence by sentence, we extracted a fragment of data around the $c l$, because there is no explicit marker to indicate sentence boundaries. We used the range of -10 to +2 words around the $c l$ in our experiments which appeared to cover most of co-occurrence patterns.

Step 4: Pattern matching

Input: Output of step 3.

Output: A list of nouns-classifiers with frequency inturmation of co-occurrences.

In this step, the tagged corpus is matched with cach pattern of classifier occurrences shown below:

N- -NCNM-CL (Enumeration)

\author{
N- -CL- in /tii/-NCNM (Ordinal expression) \\ N- -CL-DET (Referential expression) \\ N- -DET-CL \\ (Indefinite demonstration expression) \\ N- -CL-VATT (Attribute noun phrase) \\ CL-N (Noun modifier)

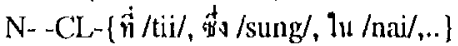 \\ (Relative/ Interrogative pronoun)
}

where $\mathrm{N}$ denotes noun, $\mathrm{CL}$ denotes classifier, NCNM denotes cardinal number, DET denotes determiner,

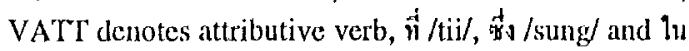
/nai/ are specific Thai words, A-B denotes a consecutive pair of $A$ and $B$, and $A-B$ denotes a possibly separated pair. Actually, A-B can be 
separated by several arbitrary words but in our experiments we considered only possible separations by a relative pronoun phrase having no more than 5 words. This is to limit the scarch space of general cases to a manageable size with some loss of generality.

The pattern matching process was carried out one by one with each pattern. For each pattern of A- $B-C$, the matching of $B-C$ pair was simple and was performed at first. Next, the matching of a pair A- $-B$ was done by:

1. scarching for the nearest $A$ from $B$. If found, mark Al.

2. from B within a span of five, searching for the ncarest relative pronoun. If found, mark $p 1$ then go to 3. Otherwisc, match A1.

3. further searching for the nearest A from $\mathrm{pl}$. If found, mark $A 2$. If $A 2$ is farther from $B$ than $A 1$, match $A 2$. Otherwise, match $A 1$.

At the end of these steps, we obtained a list of nouns $N i$ along with the frequency of $w$ in the corpus for each matching pattern (see Fig. 3.1 for sample outputs). Each entry is of the form (W_N1, CL_N2, Freq) where $\mathrm{W}$ denotes a noun, N1 denotes a number representing semantic class of $W, C L$ denotes the associated classifier, $\mathrm{N} 2$ is a number indicating whether CL is a unit or collective classifier ( 1 for unit, 2 for collective) and Freq denotes the frequency of $\mathrm{co}-$ occurrence between $\mathrm{W}$ and CL. The semantic class is shown in Fig. 3.2.

Step 5: Determine representative classifier Input: A list of noun-classifier with frequency information of co-occurrence.

Output: Representative classifier of each noun and cach scmantic class of nouns.

As it can be observed in Fig. 3.1, each noun may be used with several possible classifiers. In language generation process. However, we have to select only one of them. For each noun we select the classifier with the greatest value of co-occurrence frequency to be the representative classifier for both representative unit classificr and representative collective classifier. The classifier in Fig. 3.1, for

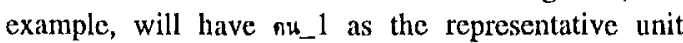
classifier and have nn:_2 as the representative collective one for the noun คณะกรรมการ_111. Collective classifiers are used instead of unit classifiers when the notion of 'group' is required.

We also find the representative classifier for each semantic class of nouns in the same manner. For each semantic class of nouns (grouped by the semantic class attached with each noun), the classifier with the greatest value of co-occurrence frequency is selected to be the representative. The classifier is used to handle the assignment of classifier to noun which does not exist in the trained corpus. For example, the representative unit classifiers for each semantic class extracted by the pattern (N- NCNM-CL) are shown in Fig. 3.3.

\section{Classifier Resolution}

The associations as produced in the previous section are useful for determining a proper classifier for a given noun. For a noun occurring in the corpus, alternative determination is accomplished in a straightforward manner by using its associated representative classifier which occurs in the corpus more frequently than any other classifiers. In the other case where the given noun does not exist in the corpus, the determination is done by using the representative classifier of its class in the concept hierarchy.

Some examples of classifier determining are listed below. (1) and (3) show the case of nouns appearing in the corpus, while (2) and (4) show a different scenario. In (2), the unit classitier of /appern/ is obtained by using the representative unit classifier of its class 'fruit' which is sูn_. 1 /luuk/ according to Fig. 3.3. Similarly, in (4), the collective classifier of /gangken/ is determined by the representative collective classifier of its class 'animal' which is ฝู่」_2 /fuung/.

\begin{tabular}{|c|c|c|}
\hline Semantic class & Unit classifier & Collective classifier \\
\hline animal & ตัว_1 & ฝูง_2 \\
human & คน__1 & คณะ_2 \\
plant & ต้น_1 & - \\
fruit & ตูก_1 & - \\
\hline
\end{tabular}

Fig. 3.3 NCA for representative classifier 
Linguistics, Vol. 19, No.3, September 1993.

\section{Unit classifier}

(1) นักเรียน คน ถู ते

/nakrian kon tii sii/

student <student> number four

(2) แย่เปิ้ล ถูก ไหน

/appern luuk nai/

apple <apple> which

\section{Collective classifier}

(3) คถะกรรมการ

คมะ นั้แ

/kanagammagarn kana nan/ committec, group that

(4) ถางข้น ผง นั้น

lgangken fuung nan/

magpic group that
[2] Nagao, Makato. (1993). "Machine Translation: What Have We to Do". Proceedings of MT Summit IV, Junc 20-22, 1993, Kobc, Japan.

[3] Noss, Richard B. (1964). Thai Reference Grammar, U.S. Government Printing Office, Washington, DC.

[4] Smadja, Frank. (1993). "Retricving Collocations from Text: Xtract". Computational Linguistics, Vol. 19, No.1, March 1993.

[5] Somlertlamvanich, Virach. (1993), "Word Segmentation for Thai in Machine Translation System", Machine Translation, National Electronics and Computer T'echnology Center, (in Thai).

\section{Conclusion}

The proposed approach is a significantly new method to manipulate the classifier phrase in Thai language. The fact that the expression of some syntactic constituents needs a specific classifier to be constructed with and the selection of classifier for cach noun or noun phrase depends on the traditional use and the semantic class. The corpus-based approach is quite suitable for detecting the traditional use and searching for the most appropriate one when it does not exist in the corpus yet. Concept hicrarchy of noun provides another path for searching when the NCA docs not cover the noun in question.

In the future, this NCA will be included in the generation process of Machine Translation to solve the classifier assigmment, and incorporated in the analysis process to produce a proper syntactic and semantic structure. The clissifier will then be a key for pattern disambiguation when it is fixed to one of the patterns illustrated in Fig. 2.1.

\section{Acknowledgement}

We wish to thank the National Electronics and Computer Technology Center (NECTEC) and Center of the International Cooperation for Computerization (CICC) who provide facilities and a large corpus base for the rescarch.

\section{References}

[1] Biber, Douglas. (1993). "Co-occurrence Patterns among Collocations: A Tool for Corpus-Based Lexical Knowledge Acquisition". Computational 



\section{Corpus-based NLP}


